\title{
Glucose Intolerance Mediated by Ghrelin through the Suppression of Insulin Secretion in Healthy Iraqi Children
}

\author{
Prof. Dr Hedef Dhafir EL-Yassin ; Zena E. Noor Aldeen, \\ Prof. Dr. Mahjoob Naffil Al Naddawi \\ Dept. of Biochemistry/College of Medicine/University of Baghdad \\ Dept of Pediatrics/College of Medicine/University of Baghdad
}

\begin{abstract}
Background:Ghrelin, identified as an endogenous ligand for the growth hormone secretagogue receptor, functions as a somatotrophic and orexigenic signal from the stomach. The secretion of ghrelin increases under conditions of negative energy balance, such as starvation, cachexia, and anorexia nervosa, whereas its expression decreases under conditions of positive energy-balance such as feeding, hyperglycemia, and obesity. In addition to having a powerful effect on the secretion of growth hormone, ghrelin stimulates food intake and transduces signals to hypothalamic regulatory nuclei that control energy homeostasis. Thus, it is interesting to note that the stomach may play an important role in not only digestion but also as a pituitary growth hormone release and central feeding regulation.

Objective:The orexigenic gut hormone ghrelin and its receptor are present in pancreatic islets. Although ghrelin reduces insulin secretion in rodents, its effect on insulin secretion in humans has not been yet established. The goal of this study was to test the hypothesis that circulating ghrelin suppresses insulin secretion in healthy children.
\end{abstract}

Subjects and methods : ELISA method was used to assay Ghrelin and Insulin. By taken blood sample from 40 obese children, 11 overweight children and 29 normal weight healthy children their age (5-11) years.

Results: the mean of Ghrelin concentration was significantly lower in obese and overweight children than in controls $(P<0.000)$. The mean of Insulin concentration was significantly higher in obese and overweight children than in controls $(P<0.007)$. Negative correlation between Ghrelin and BMI also negative correlation between Ghrelin and Insulin.

Conclusion: This study showed that ghrelin reduces insulin secretion and glucose disappearance in healthy children. This findings raise the possibility that endogenous ghrelin has a role in physiologic insulin secretion, and that it antagonists may improve $\beta$-cell function.

Keywords: Ghrelin, glucose intolerance, children

\section{Introduction}

Ghrelin has gained considerable attention over the last decade for its unique role in regulating mealtime hunger and lipid metabolism, as well as short- and long-term energy homeostasis (1). It is the only known circulating factor that promotes food intake and increases fat mass. Ghrelin is secreted mainly from the stomach and proximal small bowel, and stimulates growth hormone (GH) secretion (2), in addition to its effect on energy balance. In healthy subjects, plasma ghrelin levels rise progressively before meals and fall to a nadir within one hour after eating, with changes in plasma levels during meals varying two- to threefold (3). Under pathologic conditions associated with severe malnutrition and weight loss, such as anorexia nervosa (4), cancer, or cardiac cachexia (5), plasma total ghrelin levels are increased up to threefold compared with healthy individuals. Besides its well known effects on feeding behavior, fat mass, and GH secretion, ghrelin has recently been implicated in the regulation of glucose homeostasis (6).

The GHS receptor is expressed in the pituitary gland, the hypothalamus (arcuate and ventromedial nucleus), the hippocampus, the raphe nuclei, and the substantia nigra.(7) In addition, low-level expression has been demonstrated in a wide variety of peripheral tissues, including the gastrointestinal tract, liver, pancreas, heart, lung, kidney, adipose tissue, and even immune cells, suggesting a diverse physiologic roles for ghrelin.(8) The full-length active GHS receptor is termed GHS-1a, whereas a truncated, apparently inactive, GHS receptor isoform is termed GHS-1b.(9)

\section{Subjects and Methods}

This study was performed on 40 healthy obese children, 11 over weight and 29 normal weight children who were selected from subjects attended the public clinic in Al shaab district and from some primary schools in the region. The age of the children was between 5-11 years .

The study was carried out with the approval of the medical ethical committee in the ministry of health and the parents for blood sampling. The children were thoroughly examined by a doctor and only healthy with 
no apparent evidence of endocrine and central nervous system disorders, hypothalamic tumors and genetic syndromes were selected and then the following information were recorded.

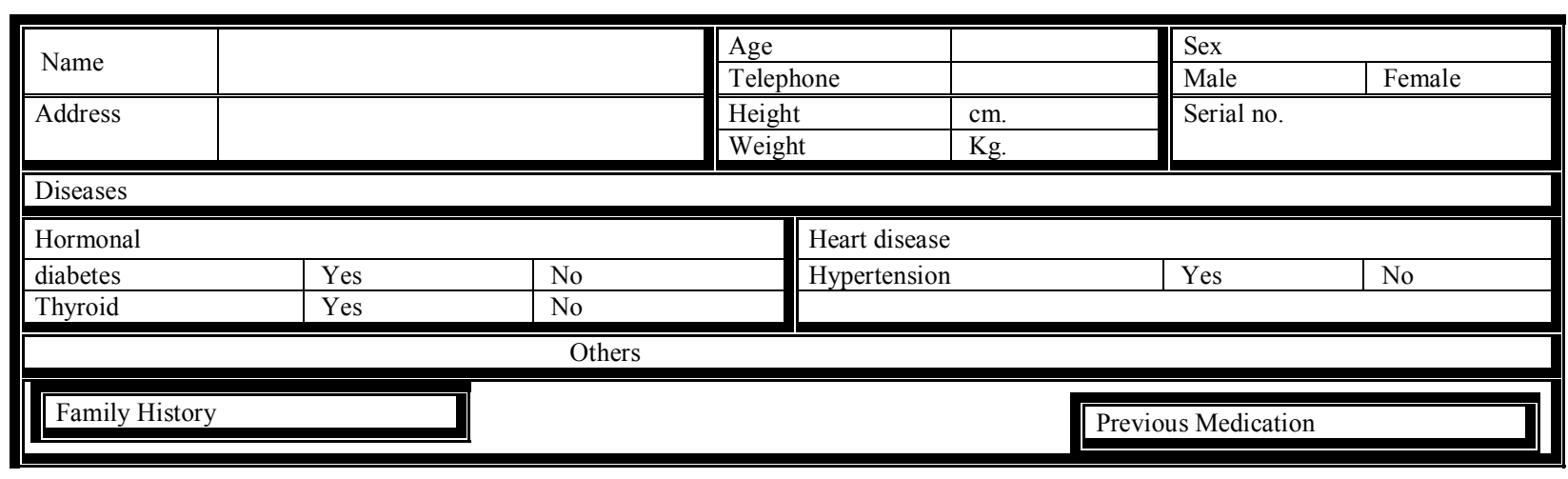

\section{Blood samples}

Five milliliters of venous blood were collected between(9-12 A.M). The blood was allowed to clot at room temperature for $30 \mathrm{~min}$. then centrifuged at(3000rpm)for 15 minutes to provide about $1.5 \mathrm{mls} 0$ f serum. The serum was then aspirated and divided into two aliquots in plain tubes. One aliquot was acidified $0.05 \mathrm{~N}$ HCL . Then kept on ice at -20c for ghrelin hormone estimation. This acidification results in a noticeable protein precipitation but does not affect the assay. The second aliquot stored on ice at $-20 \mathrm{c}$ for insulin estimation.

\section{Measurement of Ghrelin :}

This assay is a sandwich ELISA based on :

a. capture of human ghrelin molecules (both active and des-octanoyle forms)in the sample by anti -human ghrelin IgG and immobilization of the resulting complex to the wells of a microtiter plate coated by a pretittered amount of anchor antibodies,

b. and the simultaneous binding of a second biotinylated antibody to ghrelin,

c. wash away of unbound materials, followed by conjugation of horseradish peroxides to the immobilized biotinylated antibodies,

d. wash away of free enzyme, and

e. quantification of immobilized antibody-enzyme conjugates by monitoring horseradish peroxides activities in the presence of the substrate 3,3,5,5-tetra -methylbenzidine. The enzyme activity is measured spectrophoto metrically by the increased absorbency at $450 \mathrm{~nm}$, corrected from the absorbency at $590 \mathrm{~nm}$, after acidification of formed products .

Since the increase in absorbency is directly proportional to the amount of captured total human ghrelin in the unknown sample,the concentration of total ghrelin can be derived by interpolation from a reference curve generated in the same assay with reference standards of known concentration of human ghrelin. The kit supplied by DRG instruments GmbH, Germany .

\section{Measurement of insulin :}

The DEMDITEC insulin ELISA kit is a solid phase emzyme -linked immunosorbent assay (ELISA)based on the sandwich principle. The microtiter wells are coated with a monoclonal antibody directed towards a unique antigenic site on the insulin molecule. An aliquot of patient sample containing endogenous insulin is incubated in the coated well with enzyme conjugate, which is an anti-insulin antibody conjucated with biotin . after incubation the unbound conjugate is washed off. During the second incubation step streptavidin peroxidase enzyme complex binds to the biotin -anti-insulin antibody . the amount of bound HRP complex is proportional to the concentration of insulin in the sample. Having added the substrate solution, the intensity of color developed is proportional to the concentration of insulin in the patient sample. The kit supplied by DEMDITEC DIAGNOSTICS GmbH(Germany).

\section{Anthropometrical Measurement}

Body mass index (BMI) is a measure used to determine childhood overweight and obesity. It is calculated using the child's weight and height. BMI does not measure body fat directly, but it is a reasonable indicator of body fatness for most children and teens. A child's weight status is determined using an age- and sex-specific percentile for BMI rather than the BMI categories used for adults because children's body composition varies as they age and varies between boys and girls. 


\section{Statistical analysis}

Data were entered and analyzed using SPSS version 16 (SPSS Inc, USA ) for windows ( Microsoft corporation, USA ). Continuous variable were expressed as mean $\pm \mathrm{SD}$, while categorical variable were expressed as a percentage and $95 \% \mathrm{CI}$. T - test, Anova. The level of significance for all statistical test was set at 0.05 .

\section{Results}

The results in Table 1 show high level of Ghrelin in normal weight children, low level in obese and overweight children. The correlation is significant between obese and normal weight children and also between overweight and normal weight children.

Table (1):Mean , standard deviation, Median level of Ghrelin in healthy obese , over weight and normal children

\begin{tabular}{|l|l|l|l|l|l|l|l|}
\hline Group & Mean & N & Std. Deviation & Median & $\begin{array}{l}\text { Obese / Over } \\
\text { Wt }\end{array}$ & Obese / Normal & $\begin{array}{l}\text { Over } \\
\text { Normal }\end{array}$ \\
\hline Obese & 295.9428 & 40 & 81.52925 & 316.0700 & - & - & - \\
\hline Over Wt & 308.7273 & 11 & 47.04396 & 316.0700 & - & - & - \\
\hline Normal & 420.1652 & 29 & 137.55964 & 396.5700 & - & - & - \\
\hline $\begin{array}{l}\text { Mean } \\
\text { Difference }\end{array}$ & - & - & - & - & -12.78452 & $-124.22242 *$ \\
\hline Std. Error & - & - & - & - & 34.94437 & 25.03306 \\
\hline Sig. & - & - & - & - & 0.715 & 0.000 & 36.34571 \\
\hline
\end{tabular}

*. The mean difference is significant at the 0.05 level.

Table 2 results show high level of Insulin in obese and overweight children, low level in normal. The correlation is significant between obese and normal weight children.

Table (2): Mean, standard deviation, standard error of Insulin in healthy obese, over weight and normal

\begin{tabular}{|l|l|l|l|l|l|l|l|}
\multicolumn{9}{|c|}{ Group } & Mean & N & Std. Deviation & Median & Obese / Over Wt & $\begin{array}{l}\text { Obese } \\
\text { Normal }\end{array}$ & $\begin{array}{l}\text { Over Wt I } \\
\text { Normal }\end{array}$ \\
\hline Obese & 23.1258 & 40 & 23.52240 & 3.71922 & - & - & - \\
\hline Over Wt & 12.1955 & 11 & 4.89210 & 1.47502 & - & - & - \\
\hline Normal & 11.6886 & 29 & 2.71304 & 0.50380 & - & - & $11.43713 *$ \\
\hline $\begin{array}{l}\text { Mean } \\
\text { Difference }\end{array}$ & - & - & - & - & 10.93030 & 0.50683 \\
\hline Std. Error & - & - & - & - & 5.75790 & 4.12478 & 5.98880 \\
\hline Sig. & - & - & - & - & & 0.06 & 0.007 \\
\hline
\end{tabular}

*. The mean difference is significant at the 0.05 level.

The correlation between Ghrelin and Insulin is shown in figure (1)

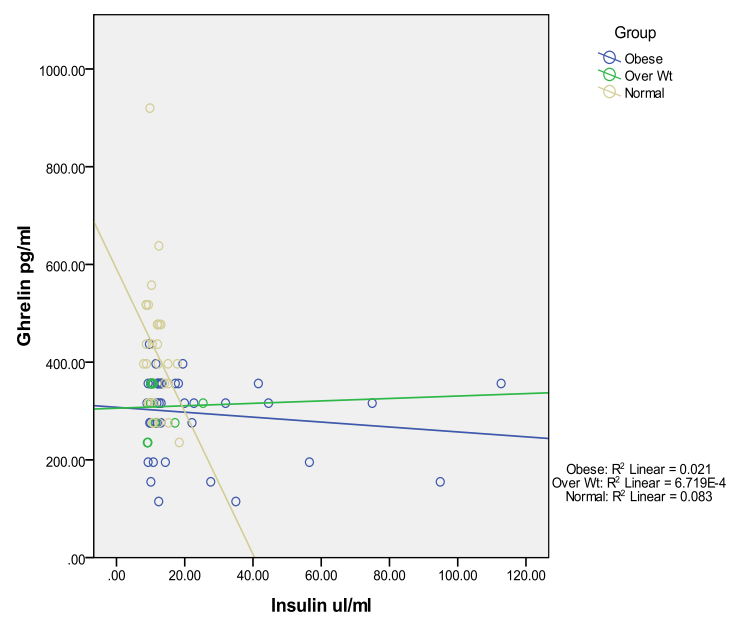

\begin{tabular}{|ll|l|l|}
\hline \multicolumn{2}{|c|}{ Group } & BMI & Insulin \\
\hline Ghrelin & Pearson Correlation & $-.454-* *$ & $-.217-$ \\
& Sig. (2-tailed) & .000 & .053 \\
& N & 80 & 80 \\
\hline
\end{tabular}


Figure (1 ) correlation between Ghrelin and Insulin among obese, over weight and normal weight children

\section{Discussion}

In table (1), the mean value of Ghrelin shows a significant difference between obese / overweight and normal weight children being low in obese ( Mean $295 \mathrm{Pg} / \mathrm{ml}$ ) and overweight while high in normal weight children ( Mean $495 \mathrm{Pg} / \mathrm{ml}, \mathrm{P}<0.000$ )

These data demonstrate that Ghrelin is involved in the control of appetite and energy balance.

Since Ghrelin acts as a ligand for the hypothalamic and pituitary GHS-RIa and exerts an orexigenic activity through the NPY/AGRP system and the orexin pathway (10) as shown in figure (2). Ghrelin appears to have a role as a long-term signal of nutritional status opposite to that of leptin. Systemic ghrelin levels are negatively associated with body adiposity and increase with weight loss induced by low-calorie diet, exercise, anorexia nervosa, or cachexia as a result of organ failure (cardiac, pulmonary, renal, or hepatic) or malignancy.(11) .

Also Ghrelin leads to increased gastrointestinal motility and (possibly) increased gastric acid secretion, which may be physiologically relevant in preparing the gastrointestinal tract to process food. (12).

In another study significant differences were found in ghrelin levels at 3 hours; ghrelin levels began recovery to baseline levels within 3 hours after food intake among obese compared to healthy children whose levels remained suppressed after 3 hours. (13)

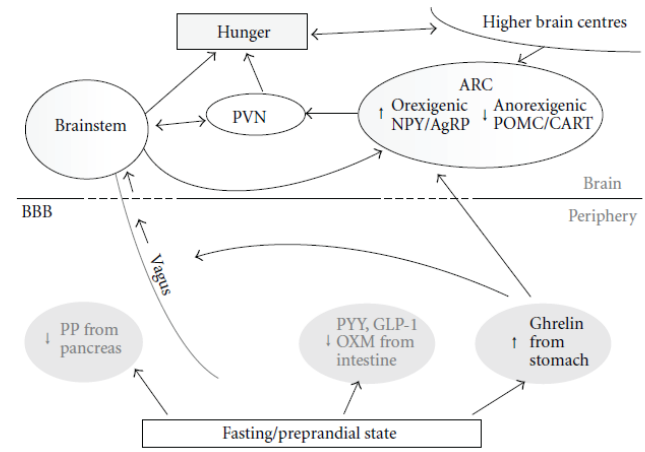

Figure (2): The gut hormone signalling to the brain under fasted. During the fasting/ preprandial state, ghrelin release from the stomach acts upon the ARC and vagus to stimulate hunger

In table (2) the mean value of Insulin shows significant difference between obese, over weight and normal weight children being high in obese and overweight (Mean 23.1258) while low in normal weight children (Mean 11.6886, $\mathrm{P}<0.000$ ). These results show that the children will predispose to insulin resistance and development of DM.

Circulating levels of insulin positively correlate with adipose tissue mass within the body. Insulin implicated in the long-term regulation of energy balance. Insulin is synthesized in the $\beta$ cells of the pancreas and is secreted rapidly after a meal, with well characterised hypoglycaemic effects (14). However, insulin also acts as an anorectic signal within the CNS. Insulin enters the CNS through a saturable and receptor-mediated transport process (15). Insulin receptors are widely expressed in the brain, particularly in hypothalamic nuclei, such as the ARC, DMN, and PVN, which are involved in control of food intake (16). Although the mechanism of insulin-mediated anorexia has not been fully elucidated, hypothalamic NPY seems to be involved.

\section{The results show the correlation as following:}

Negative correlation between Ghrelin and Insulin (figure (1)

Some but not all studies support the concept that insulin is an inhibitor of ghrelin secretion (13). Thus, obesityrelated hyperinsulinemia could at least in part be responsible for ghrelin suppression.

This finding agrees with the available data that suggest a negative association between systemic ghrelin and insulin levels.(14) Ghrelin inhibits insulin secretion both in vitro and in most human or animal studies.(15) However, other studies have suggested that ghrelin may stimulate insulin secretion in certain paradigms.(16) In addition, it is not clear whether endocrine or paracrine effects of ghrelin are more physiologically relevant in the regulation of insulin secretion.

Ghrelin inhibits insulin effects on glycogen synthesis and gluconeogenesis in vitro.(14) Ghrelin may also inhibit secretion of the insulin-sensitizing protein adiponectin from adipocytes and stimulate secretion of the counter-regulatory hormones, including GH, cortisol, epinephrine, and (possibly) glucagon.(16) More studies are needed to fully elucidate the precise physiologic role of ghrelin on the regulation of glucose homeostasis. 
The mechanisms by which ghrelin could inhibit insulin secretion are unknown. Ghrelin may exert a direct effect on the $\beta$-cell or act indirectly by stimulating the secretion of counter-regulatory hormones that affect insulin secretion, or activating neural pathways that regulate islet function (17). The signaling mechanisms for insulinostatic ghrelin action in islet $\beta$-cells have been explored. Both endogenous and exogenous ghrelin has been shown to attenuate glucose-induced insulin release via $\mathrm{G \alpha}_{\mathrm{i} 2}$ - mediated activation of $\mathrm{Kv}$ channels, and suppression of action potential firing and $\left[\mathrm{Ca}^{2}\right]_{\mathrm{i}}$ increases in $\beta$-cells (18).

\section{Conclusion:}

This study showed that ghrelin reduces insulin secretion and glucose disappearance in healthy children. This findings raise the possibility that endogenous ghrelin has a role in physiologic insulin secretion, and that ghrelin antagonists could improve $\beta$-cell function.

\section{References}

[1]. Arvat E, Di Vito L, Broglio F, Papotti M, Muccioli G, Dieguez C, CasanuevaFF, the natural GH secretagogue (GHS)-receptor ligand, strongly stimulates GH secretion in humans. J Endocrinol Invest 2000;23:493-495

[2]. Baura G. D, Foster D M, Porte D. Jr. et al., "Saturable transport of insulin from plasma into the central nervous system of dogs in vivo. A mechanism for regulated insulin delivery to the brain,” The Journal of Clinical Investigation, vol. 92, no. 4, pp. 1824-1830, 1993.

[3]. Broglio F, Arvat E, Benso A et al. Ghrelin, a natural GH secretagogue produced by the stomach, induces hyperglycemia and reduces insulin secretion in humans. J Clin Endocrinol Metab. 2001;86:5083-5086.

[4]. Castaneda TR, Tong J, Datta R, Culler M, Tschop MH. Ghrelin in the regulation of body weight and metabolism. Front Neuroendocrinol 2010; 31:44-60

[5]. Cummings DE, Purnell JQ, Frayo RS, Schmidova K, Wisse BE, Weigle DS. A preprandial rise in plasma ghrelin levels suggests a role in meal initiation in humans. Diabetes 2001;50:1714-1719.

[6]. Corp E. S, Woods S. C. Porte D, Jr., Dorsa D. M., Figlewicz D. P., and. Baskin D. G, "Localization of 125I-insulin binding sites in the rat hypothalamus by quantitative autoradiography," Neuroscience Letters, vol. 70, no. 1, pp. 17-22, 1986.

[7]. Date $\mathrm{Y}$, Kojima M, Hosoda $\mathrm{H}$ et al. Ghrelin, a novel growth hormone-releasing acylated peptide, is synthesized in a distinct endocrine cell type in the gastrointestinal tracts of rats and humans. Endocrinology. 2000;141:4255-4261.

[8]. Foster-Schubert KE, McTiernan A, Frayo RS et al. Human plasma ghrelin levels increase during a one-year exercise program. J Clin Endocrinol Metab. 2005;90:820-825.

[9]. Guan XM, Yu H, Palyha OC, McKee KK, Feighner SD, Sirinathsinghji DJ, Smith RG, Van der Ploeg LH, and Howard AD. Distribution of mRNA encoding the growth hormone secretagogue receptor in brain and peripheral tissues. Brain Res 48: 23-29, 1997.

[10]. Howard, A.D., Feighner, S.D., Cully, D.F., Arena, J.P., Liberator, P.A., Rosenblum, C.I., Hamelin, M., Hreniuk, D.L., Palyha, O.C., Anderson, J., Paress, P.S., Diaz, C., Chou, M., Liu, K.K., McKee, K.K., Pong, S.S., Chaung, L.Y., Elbrecht, A., Dashkevicz, M., Heavens, R., Rigby, M., Sirinathsinghji, D.J., Dean, D.C., Melillo, D.G. \& Van der Ploeg, L.H. A receptor in pituitary and hypothalamus that functions in growth hormone release. Science 1996, 273, 974-977.

[11]. Hattori N, Saito T, Yagyu T, Jiang BH, Kitagawa K, Inagaki C . GH, GH receptor, GH secretagogue receptor, and ghrelin expression in human T cells, B cells, and neutrophils. J Clin Endocrinol Metab. 2001;86:4284-4291.

[12]. Inui A, Asakawa A, Bowers CY et al. Ghrelin, appetite, and gastric motility: the emerging role of the stomach as an endocrine organ. FASEB J. 2004;18:439-456.

[13]. Lippl F, Kircher F, Erdmann J, Allescher HD, Schusdziarra V: Effect of GIP, GLP-1, insulin and gastrin on ghrelin release in the isolated rat stomach. Regul Pept 119:93-98, 2004.

[14]. Murata M, Okimura Y, Iida K et al. Ghrelin modulates the downstream molecules of insulin signaling in hepatoma cells. J Biol Chem. 2002;277:5667-5674

[15]. Polonsky K. S. , B. D. Given, and E. Van Cauter, "Twenty-four-hour profiles and pulsatile patterns of insulin secretion in normal and obese subjects," The Journal of Clinical Investigation, vol. 81, no. 2, pp. 442-448, 1988.

[16]. Salehi A, Dornonville de la Cour C, Hakanson R, Lundquist I . Effects of ghrelin on insulin and glucagon secretion: a study of isolated pancreatic islets and intact mice. Regul Pept. 2004;118:143-150.

[17]. Tamagawa T, Henquin JC. Epinephrine modifications of insulin release and of $86 \mathrm{Rb}$ or $45 \mathrm{Ca} 2$ fluxes in rat islets. Am $\mathrm{J}$ Physiol 1983;244:E245-E252.

[18]. Toshinai K, Date Y, Murakami N, Shimada M, Mondal MS, Shimbara T, Guan JL, Wang QP, Funahashi H, Sakurai T, Shioda S, Matsukura S, Kangawa K \& Nakazato M. Ghrelin-induced food intake is mediated via the orexin pathway. Endocrinology 2003144 1506-1512. 